\title{
Américanités francophones. Ancrages médiatiques, mises en perspective historiques et comparatistes, a cura di Hans-Jürgen Lüsebrink
}

\section{Alessandro Corio}

\section{(2) OpenEdition}

\section{Journals}

\section{Edizione digitale}

URL: http://journals.openedition.org/studifrancesi/28122

DOI: $10.4000 /$ studifrancesi.28122

ISSN: 2421-5856

\section{Editore}

Rosenberg \& Sellier

\section{Edizione cartacea}

Data di pubblicazione: 31 décembre 2006

Paginazione: 641-642

ISSN: 0039-2944

\section{Notizia bibliografica digitale}

Alessandro Corio, «Américanités francophones. Ancrages médiatiques, mises en perspective historiques et comparatistes, a cura di Hans-Jürgen Lüsebrink », Studi Francesi [Online], 150 (L | III) | 2006, online dal 30 novembre 2015, consultato il 08 novembre 2020. URL : http://journals.openedition.org/ studifrancesi/28122; DOI : https://doi.org/10.4000/studifrancesi.28122

Questo documento è stato generato automaticamente il 8 novembre 2020.

\section{cc) $($ ) $\ominus$}

Studi Francesi è distribuita con Licenza Creative Commons Attribuzione - Non commerciale - Non opere derivate 4.0 Internazionale. 


\title{
Américanités francophones. Ancrages médiatiques, mises en perspective historiques et comparatistes, a cura di Hans-Jürgen Lüsebrink
}

\author{
Alessandro Corio
}

\section{NOTIZIA}

«Globe. Revue Internationale d'Études Québécoises», Américanités francophones. Ancrages médiatiques, mises en perspective historiques et comparatistes, a cura di Hans-Jürgen LÜSEBRINK, vol. 7, 2004, n. 2, pp. 225.

Questo numero della rivista «Globe» propone un'interessante analisi a largo spettro, secondo criteri interdisciplinari, interculturali e comparatisti, del discusso fenomeno culturale dell"'americanizzazione", che caratterizza, per vari aspetti di carattere sincronico e diacronico, i processi storici in atto nella cosiddetta "globalizzazione". È altresì vero che questo termine, come molti altri utilizzati per descrivere, a volte in modo approssimativo e semplicistico, i fenomeni sociali e culturali attuali, presenta un notevole grado di ambiguità e di "polisemia" e non può certamente essere ridotto allo spauracchio di un'omogeneizzazione globale del pianeta sotto i simboli del dollaro o di Mc-Donald, né dei miti culturali di Holliwood o della dottrina neo-con della guerra "umanitaria" preventiva. Innanzitutto, la distinzione preliminare tra i due termini américanité e américanisation permette di contestualizzare l'analisi sul dominio dell'identità quebecchese e canadese francofona, per evidenziare sul doppio versante alcune modalità della ricezione della cultura americana (non solo degli Stati-Uniti) da parte delle culture francofone nordamericane, e di rintracciare omologie e differenze con altri contesti della cosiddetta "neo-america", caratterizzata dal tratto comune della 
"creolizzazione", ossia dell'interrelazione creativa di matrici culturali e storiche profondamente eterogenee.

2 Il concetto di américanité, così come è stato definito da Louis Dupont, postula l'appartenenza delle culture francofone al continente americano nelle sue dimensioni geopolitiche e culturali, ossia nei suoi caratteri geografici e storici peculiari, impregnati dalle esperienze della conquista e della colonizzazione e soprattutto dalle forti componenti multiculturali derivate dalle immigrazioni provenienti dagli orizzonti più disparati. È soprattutto a partire dagli anni Ottanta, come sottolinea Gérard BOUCHARD in Genèse des nations et cultures du Nouveau Monde, che « le thème de l'américanité (ou de la nord-américanité) a fait [...] son entrée dans le discours littéraire et artistique. Le roman a commencé à faire voyager ses héros aux Etats-Unis, à y situer une partie de ses intrigues. L'Amérique du Sud fit son apparition aussi, projetée dans une nouvelle proximité de tempérament, de culture latine» (pp. 11-12). La componente dell'“américanité" ha giocato inoltre un ruolo importante nella specificità identitaria delle culture francofone nordamericane anche nei termini di una distinzione e di uno smarcamento dalla cultura della Francia metropolitana. Su questo terreno riveste un'importanza centrale l'analisi del multilinguismo fondatore delle Americhe, che consente inoltre un parallelo con lo spazio culturale caraibico, coi temi dell'ibridazione e del "métissage" e con lo studio dei transfert culturali fra le differenti sfere linguistiche e culturali del continente americano. Per quanto riguarda il dominio letterario, le analisi in una prospettiva interculturale e comparatista di Jean-François CHASSAY e di Jean MORENCY sull'impatto del romanzo degli Stati-Uniti sulla letteratura quebecchese e delle immagini dell'America nel romanzo quebecchese contemporaneo hanno svolto un importante ruolo pionieristico (si vedano i voll. 26, 1990 e 28, 1992-1993 della rivista Études Françaises, dedicati all'«Amérique entre les langues»).

3 I lavori di Yvan LAMONDE hanno approfondito ulteriormente in senso storico questa nuova visione identitaria quebecchese e franco-canadese che la nozione di "américanité" riflette, rintracciando la genealogia, in termini foucauldiani, del concetto e del discorso dell'“américanité" e dei dispositivi culturali e mentali da questo attivati. Nel suo libro Ni avec eux ni sans eux. Le Québec et les Etats-Unis, Lamonde analizza tutta l'ambiguità e la complessità delle relazioni tra i due paesi, su un arco cronologico estremamente vasto che va dalla colonizzazione del Québec da parte dell'Impero Britannico agli anni Novanta, prendendone in considerazione gli aspetti antropologici, materiali ed intellettuali. La profonda trasformazione della società franco-canadese avvenuta nel corso degli ultimi decenni sarebbe in gran parte dovuta a questo "processus d'américanisation", incrementato dall'introduzione della modernità industriale, economica e mediatica in Québec. Gli scambi economici e culturali tra StatiUniti e Québec hanno profondamente segnato e trasformato la società franco-canadese in tutte le forme della sua cultura materiale ed intellettuale.

Il dossier presentato in questo numero della rivista si inserisce pertanto in un contesto assai variegato di analisi e ricerche sul fenomeno dell'americanizzazione, collegandosi a queste e cercando di esplorare nuove piste sul piano sia della cultura letteraria, cinematografica e artistica sia su quello della cultura materiale e della lingua. Gli articoli di Yvan Lamonde (Américanité e américanisation. Essai de mise à point, pp. 21-29) e di Jean Morency (L'américanité et l'américanisation du roman québecois. Reflexions conceptuelles et perspectives littéraires, pp. 31-58) rintracciano, nel dominio socioculturale e storico, da una parte, e letterario, dall'altra, la portata e le implicazioni delle 
nozioni di "américanité" e di "américanisation", offrendo entrambi una vasta presentazione delle ricerche effettuate in questo campo. Lamonde insiste sull'“américanité" come componente fondamentale dell'identità franco-canadese, mostrando al tempo stesso che questa nozione ha sempre implicato «une critique sinon un refus d'impérialisme états-unien». Morency propone invece una distinzione estremamente utile tra l'“américanisation" - generalmente associata ad un consumo passivo della cultura e ad un processo di acculturazione e di imitazione ricettive - e l'“américanité" - che designa il lato positivo dell'americanizzazione, implicando delle influenze liberamente scelte e dei transfert culturali coscienti e attivi. Constatando che le due nozioni-processi si intersecano, l'autore si prefigge di studiare i variegati fenomeni di natura interculturale che li caratterizzano, dagli usi intertestuali ed interdiscorsivi ai fenomeni di traduzione e di adattamento, caratterizzati da pratiche di invenzione di forme culturali ibride.

Ute FENDLER e Christoph VATTER (Évangéline multimédia. Un mythe acadien entre américanité et américanisation, pp. 59-79), si concentrano sulle metamorfosi inter-mediatiche ed intertestuali del mito di Évangéline nel Canada francofono e negli Stati-Uniti a partire dal XIX secolo. Attraverso un'analisi che spazia dai film alle commedie musicali ai testi letterari, questo studio mette in luce come le nozioni di "américanité" e di "américanisation" si iscrivano nella storia inter-mediatica di un mito collettivo, mettendo a confronto forme di appropriazione da parte della cultura di massa americana e ri-appropriazioni, riletture e decostruzioni francofone, segno di un'americanità liberamente rivendicata. L'articolo di Hans-Jürgen LÜsEBRINCK (Interculturalités américaines. La trajectoire de Paul-Marc Sauvalle, cosmopolite canadienfrançais, pp. 81-99) rintraccia invece la traiettoria biografica transamericana del giornalista e scrittore Paul-Marc Sauvalle, francese di origine ed immigrato in Canada nel 1884, che attraverso un percorso personale estremamente ricco che lo conduce in Louisiana, in Messico, negli Stati-Uniti e in Canada, rappresenta un vero e proprio precursore dell'americanità contemporanea, vera e propria interfaccia tre le "tre americhe": francofona, anglofona ed ispanofona.

Infine, gli articoli di Beatrice BAGOLA (L'américanisation de la langue française sur Internet? Quelques aspects de la terminologie officielle et de l'usage des internautes, pp. 101-124) e di Katrin MUTZ (Le lexique des variétés du français en Louisiane et l'influence de l'anglo-américain. Un état de recherche, pp. 125-154) affrontano la dimensione linguistica del fenomeno dell'americanizzazione. Bagola affronta lo spazio rispettivo dell'inglese e del francese su Internet ed analizza la concorrenza tra le due terminologie, notando importanti differenze tra la Francia e il Québec. Mutz, da parte sua, studia l'impatto dell'inglese sul francese in Louisiana, mostrando, a partire da numerose ricerche socio-linguistiche, il continuo ritrarsi del francese a partire dal XIX secolo, e il suo carattere moribondo oggidì, nonostante i continui sforzi istituzionali.

Questa miscellanea ben orchestrata di studi, in un campo che resta aperto ed estremamente sfaccettato, ci offre un ottimo punto di partenza per affrontare una serie di questioni, di carattere culturale e storico-sociale, che riguardano, con enormi differenze, ma anche notevoli punti di comunanza, i cambiamenti in atto a livello planetario e le interrelazioni tra flussi culturali globali e costruzioni identitarie locali e che necessitano, per essere analizzati e compresi, di approcci interdisciplinari improntati ad un'analisi della complessità. 